[This is a pre-publication version of tis paper. The final version appears in Oran Doyle and William Binchy (eds), Committed Relationships and the Law (Dublin: Four Courts Press, 2007)]

\title{
Moral Argument and the Recognition of Same-Sex Partnerships
}

\section{Introduction}

Writing in the US context, Carlos Ball attempts to justify the use of moral argument by a gay rights advocate. He begins by noting how such arguments have traditionally been eschewed by gay rights advocates:

For most of the history of the gay rights movement in the United States, it has been possible and even advisable for its supporters to avoid engaging questions of morality directly. Arguments based on notions of morality have been used primarily by opponents of gay rights to justify the differential treatment by society of lesbians and gay men. It is the purported immorality of a gay and lesbian sexuality, for example, that justifies in the minds of some denying samegender couples the right to marry.... In response to these and other familiar arguments raised by opponents of gay rights about the immorality of gay and lesbian sexuality and relationships, most supporters of gay rights (including political activists and academics) prefer to sidestep moral arguments altogether and instead rely on what are taken to be morally neutral (and largely liberal) arguments based on considerations of privacy, equality and tolerance. ${ }^{1}$

Ball refers to this avoidance of moral arguments as "moral bracketing" - a "strict separation of moral, philosophical, and religious views ... from considerations of justice". ${ }^{2}$ This moral bracketing, sometimes phrased as a right to privacy in matters of sexual intimacy, well served the political objective of the decriminalisation of homosexual activity. ${ }^{3}$ Ball argues, however, that most of the controversies over homosexuality are moral controversies. Correctly, in my view, he argues that "even the paradigmatic right to privacy in matters of sexual intimacy ... is most convincingly grounded on a moral

\footnotetext{
${ }^{1}$ Carlos A. Ball, The Morality of Gay Rights (Routledge, London, 2003), at 1.

2 Carlos A. Ball, The Morality of Gay Rights (Routledge, London, 2003), at 1.

${ }^{3}$ Ball also argues that moral bracketing even, in the form of neutral equality arguments, provided the basis for obtaining from the state the protection afforded by anti-discrimination legislation. I am not as convinced on this point as, I think, any detailed examination of the "relevance" criterion that tends to
} 
conception of the potential for human flourishing that inheres in the exercise of selfdetermination or autonomy". Claims that the State should provide recognition for samesex partnerships necessarily require some argument as to why such recognition should be provided: these are moral arguments. ${ }^{5}$ Intellectual honesty and political expediency combine: gay rights advocates must rely on moral arguments.

Now I do not conceive of myself as a gay rights advocate, although perhaps that is (part of) what I am. More particularly, my purpose in this paper is not to construct the most convincing moral argument in support of the recognition of same-sex partnerships. Rather my purpose is to examine a number of moral arguments advanced in support of and against such recognition. My selection of arguments is, as will quickly become apparent, far from exhaustive. I focus on natural law arguments against partnership recognition and egalitarian arguments in favour of recognition. My basis for focusing on natural law arguments is my intuition that arguments against the recognition of same-sex partnerships are at root moral arguments that rely on some natural law type account of human sexuality. My basis for focusing on egalitarian arguments is my intuition that equality provides the most compelling basis on which to argue for partnership recognition. Clearly my argument is incomplete, but my hope is to make some contribution to those aspects of this debate that I have chosen, somewhat arbitrarily, to focus on. Within these limits, the purpose of this paper is ultimately two-fold: first, to assess whether some recognition of same-sex partnerships is morally permissible or required; secondly and if so, to assess which form of recognition best reflects the moral argument that justified recognition in the first instance.

Two points that generally cause difficulty must be clarified. First, as noted above, I agree with Ball's contention that rights to privacy, whereby the state allows to the individual a zone of personal autonomy within which to make her own choices, are themselves moral propositions. Notwithstanding that the substance of the right is the non-imposition of the state's moral code within that zone of autonomy, the belief that the state should not impose its moral code is itself a moral belief. It is a moral belief about the importance of

inform such legislation shows that it is not neutral and, indeed, imports moral arguments. Given Ball's later comments on moral argument in general, I suspect that he might agree with this observation.

${ }^{4}$ Carlos A. Ball, The Morality of Gay Rights (Routledge, London, 2003), at 5.

${ }^{5}$ Although it is possible to argue that recognition should be provided to all relationships unless there is a good reason not to, this does not seem a particularly attractive proposition. In any event, it requires moral 
individual autonomy in certain areas. Some advocates of such a right might agree with this characterisation; others might not. For the purposes of this paper, whether one agrees with the characterisation or not is irrelevant. Privacy rights rest on moral beliefs about the appropriate limits on the actions of the state.

Secondly, the word "moral" is itself, in a very literal way, ambiguous. This becomes clear if one considers how the word "moral" is the opposite of two other words: "amoral" and "immoral". "Amoral" is essentially a descriptive word, connoting (although this meaning may have been hijacked) "having nothing to do with issues of right or wrong". "Immoral" is an evaluative word, connoting "against a code of what constitutes right or wrong". Thus the word "moral" itself must have two meanings: one descriptive, one evaluative. Used in the descriptive sense, a "moral" proposition is one that purports to provide a reason for behaving or not behaving in a particular way. Used in the evaluative sense, a "moral" proposition is one that truly does provide a reason for behaving or not behaving in a particular way. The purpose of this essay is to assess moral (in the descriptive sense) arguments in order to identify the moral (in the evaluative sense) position on the recognition of same-sex partnerships.

I shall begin with an examination of Finnis's natural law theory and his particular application of that to the question of partnership recognition. Although there are many variants of natural law theory, I focus on Finnis for the reason that he advances a natural law argument that unequivocally rejects the civil recognition of same-sex partnerships. If I can show Finnis's argument to be unfounded, my case is stronger than if I had undermined a natural law theory that was more moderate in its approach. Having considered Finnis's argument, I shall consider egalitarian arguments in favour of partnership recognition. In doing so, my primary concern (in this paper) is to defend egalitarian arguments against the general claim that there are no valid egalitarian arguments. I shall conclude with an assessment, in the light of egalitarian arguments, of various forms of partnership recognition currently under discussion.

\section{The Natural Law Argument}

Outline of the natural law argument against partnership recognition

argument to support the proposition that recognition should presumptively be provided to all relationships. In the context of positive state action (at the very least), moral arguments are unavoidable. 
Finnis articulates a natural law argument against the recognition of same-sex partnerships. ${ }^{6}$ In outline, this argument is as follows: marriage (ie the presumptively procreative union of a man and a woman) is a basic good; it is impermissible to intend to destroy, damage, impede or violate any basic human good or to prefer an illusory instantiation of a basic human good to a real instantiation of that or some other human good; accordingly, the state should not recognise and thus legitimise same-sex partnerships, as these partnerships are illusory representations of the basic good of marriage and thus inimical to that basic good. In order to understand and evaluate this argument, it is necessary to understand the broad outlines of Finnis's natural law argumentation.

\section{Finnis's theory of natural law}

Finnis asserts that there are seven basic values or goods: life, knowledge, play, aesthetic experience, sociability (friendship), practical reasonableness and religion. These goods are not themselves moral propositions, but are rather basic facts about human nature on which moral argument is based. In establishing that something is a basic good or value, Finnis seems to place most importance on two discrete observations. The first is the observation of an inclination; the second is the observation of the grasp of value. Finnis considers these in the context of knowledge. He notes that "curiosity" is a name for the inclination that we have when, just for the sake of knowing, we want to find out about something. ${ }^{7}$ However, there is more to this than just inclination for, on reflection, one can perceive that there is a good in this inclination:

Commonly one's interest in knowledge, in getting to the truth of the matter, is not bounded by the particular questions that first aroused one's desire to find out. So readily that one notices the transition only by an effort of reflection, it becomes clear that knowledge is a good thing to have (and not merely for its utility), without restriction to the subject-matters that up to now have aroused one's curiosity. ${ }^{8}$

Thus, basic goods are identified by both inclination and grasp of value. It is not sufficient that there be a common urge to do a particular thing, there must also be a sense of the

\footnotetext{
6John M. Finnis, "Law, Morality and Sexual Orientation” 69 Notre Dame Law Review 1049 (1994).

${ }^{7}$ John M. Finnis, Natural Law and Natural Rights (Clarendon, Oxford, 1980), at 60.

${ }^{8}$ Finnis, Natural Law and Natural Rights, at 61.
} 
worthwhileness of doing that thing. Finnis undertakes a similar, although abbreviated exercise, in respect of the other basic goods.

Three points must, in particular, be noted about the basic goods. First, they are selfevident. Finnis asserts, for instance, that the good of knowledge is "self-evident, obvious"; it cannot be demonstrated, but equally it needs no demonstration. This does not mean, however, that it is self-evident to everyone:

On the contrary, the value of truth becomes obvious only to one who has experienced the urge to question, who has grasped the connection between question and answer, who understands that knowledge is constituted by correct answers to particular questions, and who is aware of the possibility of further questions and of other questioners who like himself could enjoy the advantage of attaining correct answers. ${ }^{9}$

This self-evidence is a proposition of rationality, not psychology. The soundness of the assertion that knowledge is a self-evident good is not addressed by any inquiry into the physical, biological or psychological conditions under which a person might make such an assertion. The issue of value is not addressed by such factual inquiries. Conversely, one should not commit the naturalistic fallacy and attempt to derive value from purely factual observations:

$[1] \mathrm{f}$ one is to go beyond the felt urge of curiosity to an understanding grasp of the value of knowledge, one certainly must know at least the fact that questions can be answered. Moreover, one certainly will be assisted if one also knows such facts as that answers tend to hang together in systems that tend to be illuminating over as wide a range as the data which simulate one's questions. But one who, thus knowing the possibility of attaining truth, is enable thereby to grasp the value of that possible object and attainment is not inferring the value from the possibility. No such inference is possible. No value can be deduced or otherwise inferred from a fact or set of facts. ${ }^{10}$

\footnotetext{
${ }^{9}$ Finnis, Natural Law and Natural Rights, at 65. This amounts to little more than a declaration that those who consider knowledge important think knowledge important, thus offering little independent support for the contention that knowledge is a basic good. However, this perhaps misses the point: the whole point of selfevident goods is that they cannot be justified by reference to something else. They are self-evident.

${ }^{10}$ Finnis, Natural Law and Natural Rights, at 66.
} 
Similarly one cannot infer the value of knowledge from the mere fact that all people desire to know, nor from the mere fact that all people not only desire to know but also affirm the value of knowledge. Conversely, the mere fact that not all people desire to know or that not all people affirm the value of knowledge is not sufficient ground for denying the self-evident good of knowledge. The self-evidence of the goodness of knowledge boils down to the following: it can be denied, for it is not a principle of logic conformity to which is essential if one is to mean anything, but to deny it is "to disqualify oneself from the pursuit of knowledge"; it is as "straightforwardly unreasonable as anything can be". ${ }^{11}$

The second point to be noted about basic goods is that they are basic. That is, they are not instrumental to other goods; they are irreducible. Thus, when Finnis speaks of knowledge, he is more precisely speaking about speculative knowledge. That is, he speaks of knowledge for its own sake rather than knowledge as instrumental to some other end, such as money-saving, personal advancement or, indeed, other goods such as environmental protection or the preservation of life. This is not to say that knowledge for other ends is not a good, but simply that it is not an instantiation of knowledge as a basic good.

The third point to be noted about basic goods is that they are not moral propositions. They do not of themselves and in the abstract possess moral force; they do not of themselves and in the abstract direct that certain things should be done or not done, allowed or disallowed. It is through the good of practical reasonableness that the basic goods are brought to bear on particular situations. This represents the (moral) natural law method of working out the natural law from the first (pre-moral) principles of natural law.

In working out such a stance, Finnis identifies a number of basic requirements of practical reasonableness. I propose only to outline these here in order to provide a rough sense of the character of moral reasoning, as envisaged by Finnis. First, one should adopt

\footnotetext{
${ }^{11}$ Finnis, Natural Law and Natural Rights, at 69. Again, however, the circularity is plain: why does it matter if one disqualifies oneself from the pursuit of knowledge unless one first accepts that knowledge is a basic good?
} 
a rational and coherent plan of life: this requires one to view one's life as a whole. ${ }^{12}$ Secondly, one should adopt no arbitrary preference amongst the basic values. Although any coherent plan of life requires one to concentrate on one or some of the basic goods, such a commitment is rational only if it is made on the basis of one's assessment of one's capacities, circumstances and tastes. It would be unreasonable to concentrate one's efforts in this way as a result of a devaluation of one of the basic goods. ${ }^{13}$ Thirdly, one should not have arbitrary preferences among persons. Fourthly and fifthly, one must maintain a certain detachment from one's projects (such that one would not consider one's life as devoid of meaning if one project were to fail) and yet, at the same time, one should be committed to one's projects, having undertaken them. Sixthly, the consequences of particular courses of actions have a certain, though limited, relevance for the morality of choosing one course of action over another; efficiency can be taken into account to a limited extent.

Seventhly - and of particular importance for Finnis's later arguments in relation to the recognition of same-sex partnerships - "one should not choose to do any act which of itself does nothing but damage or impede a realization or participation of any one or more of the basic forms of human good". ${ }^{14}$ This injunction applies, Finnis argues, because the only reason for doing such an act would be that its good consequences outweighed the damage done in and through the act itself. Such reasoning involves a necessarily arbitrary and delusive, and hence inappropriate, consequentialist weighing. As the goods are equally basic and do not share any common essence, they are incommensurable: they cannot be weighed against each other in the manner required by consequentialist logic.

There is a distinction, Finnis argues, between acts which promote one basic good but indirectly damage another basic good and acts which do nothing but damage basic goods. ${ }^{15}$ The latter are prohibited; the former may be permitted:

\footnotetext{
12 Natural Law and Natural Rights, at 103-105.

13 Natural Law and Natural Rights, at 105-106.

14 Natural Law and Natural Rights, at 118. Emphasis original.

15 Such indirect damage is inevitable given that, for example, time expended promoting one basic good (for instance, knowledge) is time taken away from the promotion of another basic good (for instance, life). These moral propositions amount, I think, to what is commonly referred to as the doctrine of indirect effect. Finnis notes that this raises the problem of individuating actions; i.e. if one characterises an action as individual, one implicitly treats the consequences of that action as individual and as actions in themselves. Accordingly, the consequences cannot be seen as indirect effects of a morally good action. On the other
} 
$[\mathrm{T}] \mathrm{o}$ indirectly damage any basic good (by choosing an act that directly and immediately promotes either that basic good in some other aspect or participation, or some other basic good or goods) is obviously quite different, rationally and thus morally, from directly and immediately damaging a basic good in some aspect or participation by choosing an act which in and of itself simply (or, we should now add, primarily) damages that good in some aspect or participation but which indirectly, via the mediation of expected consequences, is to promote either that good in some other aspect or participation, or some other basic $\operatorname{good}(\mathrm{s}) .^{16}$

Clearly, the key problem here is how to differentiate between those acts which indirectly damage a basic good and those acts which directly damage a basic goods. Finnis describes this as a problem of individuating acts. If an act is individuated, it follows that its consequences are also individuated acts. If an act is not individuated, it follows that its consequences can be seen as part of the one act, and hence as indirect effects. We decide whether an act is individuated by reference to "those factors which we gesture towards with the word 'intention"':

Fundamentally, a human act is a that-which-is-decided-upon (or -chosen) and its primary proper description is as what-is-chosen. A human action, to be humanly regarded, is to be characterized in the way it was characterized in the conclusion to the relevant train of practical reasoning of the man who chose to do it. On the other hand, the world with its material (including our bodily selves) and its structures of physical and psycho-physical causality is not indefinitely malleable by human intention. The man who is deciding what to do cannot reasonably shut his eyes to the causal structure of his project; he cannot characterize his plans ad lib. ${ }^{17}$

Eighthly, one must favour and foster the common good of one's community. Ninthly and finally, one must follow one's own conscience: thus if one decides to do what one believes is wrong, one breaches a requirement of practical reasonableness.

hand, if an action is not individuated, its consequences can be seen as indirect effects and therefore permissible. Natural Law and Natural Rights, at 119.

16 Natural Law and Natural Rights, at 120.

17 Natural Law and Natural Rights, at 122. Internal cross-references omitted. 
For Finnis, morality is the product of these requirements. Each of these requirements provides a reason for acting or not acting in a particular way. Put together, they constitute morality. Therefore, it is not permissible to rely on one of the requirements, say efficiency, to the expense of the others. Morally sound judgments can only be reached if all the requirements of practical reason are taken into account.

\section{Finnis and the criminalisation of same-sex activity}

Finnis identifies a particular position on homosexuality (at the time described as the "modern [European] position", ${ }^{18}$ although this description might now require change) whereby criminalisation of homosexual activity or conduct is considered wrong and unreasonable discrimination by public bodies against homosexuals is prohibited. However, the other side of this position is that it does not outlaw discrimination by private persons against homosexuals and it discourages the promotion of forms of life which both encourage homosexual activity and present it as a valid or acceptable alternative to committed heterosexual union. Although this position might at first appear contradictory as to the moral character of homosexual activity, it is explicable - in Finnis's view - by reference to the concept of subsidiarity. Thus the position identified by Finnis unequivocally views homosexual activity as morally wrong, but also considers that "the state's proper responsibility for upholding true worth (morality) is a responsibility subsidiary (auxiliary) to the primary responsibility of parents and non-political voluntary associations". ${ }^{19}$ Under this account, the state does not assume a directly parental disciplinary role in relation to consenting adults. On the basis of this, a distinction is drawn between supervising the truly private conduct of adults and supervising the public realm. The public realm is particularly important as it is there that the young are educated and assisted in avoiding bad forms of life. ${ }^{20}$ The supervision of that public realm is an important "part of the state's justification for claiming legitimately the loyalty of its decent citizens". ${ }^{21}$

\footnotetext{
${ }^{18}$ Finnis, "Law, Morality and Sexual Orientation", at 1051.

${ }^{19}$ Finnis, "Law, Morality and Sexual Orientation", at 1052. Emphasis original

20 Although Finnis provides other grounds for the different roles afforded to the state in the public and private realms respectively, this ground may prove problematic or at least more complicated and in need of greater explanation. There are families in which for morally unsound reasons (on Finnis's terms), younger members of the family are encouraged to view homosexual activity and same-sex relationships as acceptable and praiseworthy. It is unclear whether the principle of subsidiary is capable of supporting the public/private distinction in this context.
} 
Thus Finnis advances an avowedly moral argument against the recognition of same-sex partnerships that does not extend to the criminalisation of same-sex activity or conduct. This argument, although based on sophisticated moral reasoning, employs as a determining criterion the public/private distinction. As such, it is not far removed from liberal arguments for privacy and individual autonomy, although it adopts a position on what constitutes a morally acceptable exercise of individual autonomy that would probably find little favour with most who classify themselves as liberals. For present purposes, however, it suffices to note that Finnis's argument against the recognition of same-sex partnerships, although based to a certain extent on the immorality of same-sex conduct, does not extend to the criminalisation of such conduct. Although this point is important in itself, it also demonstrates that Finnis's argument cannot plausibly be criticised on the grounds that it represents an unwarranted interference with personal liberty.

\section{Same-sex partnerships, marriages and basic goods}

Imagine an unsophisticated political debate about homosexuality and, in particular, about the recognition of same-sex partnerships. An unsophisticated supporter of such recognition might rely on hazy propositions of equality and personal freedom. An unsophisticated opponent of recognition might adopt a position against homosexual activity on the basis of its unnatural (by which is meant non-procreative) characteristics. On the basis of this, she argues, the state should prohibit such activity or, at the very least, deny recognition to relationships in which such activity (we assume) will take place. Our supporter of such recognition responds by arguing that non-procreation is also a feature of much heterosexual activity (even in the absence of contraception) and of many heterosexual marriages, at least for certain periods, whether through choice or capacity. Accordingly, she concludes, the non-procreative characteristic of same-sex activity does not justify a position criminalising same-sex activity or denying the recognition of samesex partnerships. Our opponent of recognition, not to be outdone, responds that marriage is not just about procreation, however; it is also about care and companionship. Aha, our supporter concludes, same-sex partners can also demonstrate care and companionship: if that is the basis for recognition of heterosexual marriage, we should also recognise same-sex partnerships.

\footnotetext{
${ }^{21}$ Finnis, "Law, Morality and Sexual Orientation", at 1053.
} 
This is in many ways an unsatisfactory argument. The supporter of recognition fails to specify or justify the appropriate default position for the debate: recognition or non recognition? In particular, the positive arguments in favour of such recognition are not clearly spelt out. The opponent of recognition, on the other hand, probably commits the naturalistic fallacy in deriving moral propositions from observations of biological facts. Finnis, in particular, would make no such claim. As already discussed, his moral argumentation consists of the exercise of practical reason in choosing to act - or not act - in order to promote one of the basic goods. For these reasons, I am not identifying the position of any theorist with the arguments put forward by my imagined supporter and opponent of recognition. However, their discussion does highlight a feature in this debate. A natural law theorist, if she is to justify non-recognition of same-sex partnerships at the same time as recognition, in the form of marriage or otherwise, of heterosexual partnerships, cannot rely simply on the basic good of life (or procreation) as that would seem to preclude recognition of some marriages - it is an under-inclusive rationale. However, if she relies on the basic good of friendship, it would seem to include recognition of same-sex partnerships - it is an over-inclusive rationale. If the recognition of marriage is justified in terms of either of these basic goods (in other words, if marriage is viewed as a secondary good, instrumental to one or more basic goods), the moral position against the recognition of same-sex partnerships and, indeed, against same-sex activity is undermined.

I have set out this argument in some detail because I see Finnis's argument against the recognition of same-sex partnerships as being a response to it, although he does not state it as explicitly as I have done. For Finnis articulates a position against the recognition of same-sex partnerships that is based on none of the basic, self-evident goods identified in Natural Law and Natural Rights but rather on the new basic good of marriage:

[I]n sterile and fertile marriages alike, the communion, companionship, societas and amicitia of the spouses - their being married - is the very good of marriage, and is an intrinsic, basic human good, not merely instrumental to any other good. And this communion of married life, this integral amalgamation of the lives of the two persons ... has as its intrinsic elements, as essential parts of one and the same good, the goods and ends to which the theological tradition, following Augustine, for a long time subordinated that communion.... Parenthood and 
children and family are the intrinsic fulfilment of a communion which, because it is not merely instrumental, can exist and fulfil the spouses even if procreation happens to be impossible for them. ${ }^{22}$

Thus marriage is itself a basic good; it is - contrary to earlier church teaching - neither subordinate nor instrumental to other goods, such as life (procreation) or friendship. Such goods are intrinsic and essential parts of marriage, but marriage is itself a primary good. By this stage, it should be obvious that, marriage being a basic good, other forms of relationship will be deemed morally dubious. Nevertheless, it is worth considering Finnis's argument in some detail as it throws light on a number of other issues.

Procreation and friendship are essential elements of marriage: they make marriage what it is. But marriage itself is a basic good: the sexual union of wife and husband within marriage makes them one reality and allows them experience their real common good, their marriage. Outside of marriage, sexual union does not allow for the experience of such common good, because there is no common good being served by the union. This, for Finnis, is particularly the case in respect of the sexual acts of same-sex partners:

[T] hose acts cannot express or do more than is expressed or done if two strangers engage in such activity to give each other pleasure, or a prostitute pleasures a client to give him pleasure in return for money, or (say) a man masturbates to give himself pleasure and a fantasy of more human relationships after a gruelling day on the assembly line.... [T] here is no important distinction in essential moral worthiness between solitary masturbation, being sodimized as a prostitute, and being sodomized for the pleasure of it. ${ }^{23}$

Sexual acts can only be "unitive" in their significance if they are marital. This is not a licence for non-procreative sexual acts within marriage, however, as owing to the good of marriage having two essential elements (procreation and friendship) sexual acts are not marital unless they are acts both of friendship and of procreative significance. "Procreative significance" does not mean being capable of generating or intended to generate but rather means being acts of the reproductive kind. Acts of procreative significance would thus, presumably, include unprotected vaginal intercourse between a

${ }^{22}$ Finnis, "Law, Morality and Sexual Orientation", at 1054-1055. Emphasis original. 
woman and a man (even if one or both parties is sterile), but not (artificially?) protected vaginal intercourse or any other types of intercourse.

Finnis's assertions here must be understood in their proper context. He relies on no empirical, anecdotal nor, presumably, experiential basis for his comments about the characteristics of same-sex activity. His assertions, I think, do not purport to be factual descriptions in that sense. This is not to say, however, that his assertions are counterfactual. Rather, his assertions are evaluative descriptions of a world in which marriage is a basic good. The described characteristics of homosexual activity cannot be taken as independent support for his moral views, let alone for his assertion that marriage is a self-evident good. If nothing else, this would infringe Finnis's own injunction against reliance on the naturalistic fallacy. Rather, the described characteristics are incidents of a reality in which marriage is a self-evident good. Although both the status of marriage as a self-evident good and the characteristics of homosexual activity are important parts of Finnis's overall moral position, only the former is of argumentative significance, as it is the former that determines the latter. Finnis's argument, that is, turns on the status of marriage as a self-evident good and not (directly at any rate) on his described characteristics of homosexual activity.

\section{Communal self-delusion and false instantiation of basic buman goods}

The final step in Finnis's argument is that non-marital sexual unions represent illusory instantiations of a basic human good. It is a moral principle, as seen earlier, that one may never intend to destroy, damage, impede, or violate any basic human good, or prefer an illusory instantiation of a basic human good to a real instantiation of that or some other human good. It is this proposition that transforms same-sex partnerships into something specifically and radically immoral, something that no state, attempting to achieve the common good of its citizens, should countenance. Same-sex partnerships are not simply inimical to those who take part in them (as private same-sex activity might arguably be):

[The deliberate genital coupling of persons of the same sex] treats human sexual capacities in a way which is deeply hostile to the self-understanding of those members of the community who are willing to commit themselves to real marriage in the understanding that its sexual joys are not mere instruments or

\footnotetext{
${ }^{23}$ Finnis, "Law, Morality and Sexual Orientation", at 1067.
} 
accompaniments to, or mere compensations for the accomplishment of marriage's responsibilities, but rather enable the spouses to actualize and experience their intelligent commitment to share in those responsibilities, in that genuine self-giving. ${ }^{24}$

In Finnis's view, one can only view homosexual acts as acceptable if one views sexual capacities, organs and acts as instruments for gratifying the individual selves who have them. In his view, such an acceptance is itself inimical to marriages:

A political community which judges that the stability and protective and educative generosity of family life is of fundamental importance to that community's present and future can rightly judge that it has a compelling interest in denying that homosexual conduct - a "gay lifestyle" - is a valid, humanly acceptable choice and form of life, and in doing whatever it properly can, as a community with uniquely wide but still subsidiary functions, to discourage such conduct. $^{25}$

\section{Problem with Finnis's argument: marriage as a self-evident good}

As noted above, in 1980 Finnis identified only seven self-evident goods, not including marriage. Although he noted that the list was not exhaustive, he did make a number of important methodological points about any tendency to recognise further self-evident basic goods. These methodological points provide good reasons not to identify marriage as a basic, self-evident good and thus require further consideration.

Finnis recognises that, as well as the seven self-evident basic goods, there are countless objectives and forms of good. But he suggests:

$[\mathrm{T}]$ hese other objectives and forms of good will be found, on analysis, to be ways or combinations of ways of pursuing (not always sensibly) and realizing (not always successfully) one of the seven basic forms of good, or some combination of them. ${ }^{26}$

\footnotetext{
${ }^{24}$ Finnis, "Law, Morality and Sexual Orientation", at 1069. Emphasis original.

${ }^{25}$ Finnis, "Law, Morality and Sexual Orientation", at 1070.

${ }^{26}$ Finnis, Natural Law and Natural Rights, at 90. Emphasis added.
} 
He accepts that there might be more than seven self-evident basic goods and that people might reasonably not accept his list, still less his nomenclature - the words "life", "knowledge" and so on simply gesture "towards categories of human purpose that are each, though unified, nevertheless multi-faceted". ${ }^{27}$ But again he makes the point:

Still, it seems to me that those seven purposes are all of the basic purposes of human action, and that any other purpose which you or I might recognize and pursue will turn out to represent, or be constituted of, some aspect(s) of some or all of them. ${ }^{28}$

Thus Finnis strongly, although not dogmatically, maintains that there are only seven selfevident basic goods. He further suggests that any inclination to identify other forms of good as further self-evident basic goods is probably mistaken for one of two reasons. Either the new form of good is a means to achieving a basic self-evident good. Or the new form of good is a representation or combination of a number of basic self-evident goods. Neither of these propositions means that the new form of good is no longer good nor worth pursuing. Rather, their import is simply that the good should not be perceived as a basic, self-evident good in its own right.

Each of these injunctions seems apposite to Finnis's subsequent identification of marriage as a basic, self-evident good. His reasoning on this, as set out above, is that marriage is a good comprised of both life and friendship. However, applying Finnis's own reasoning from Natural Law and Natural Rights, one should probably reject that as a basis for the assertion of marriage as a self-evident good. That assertion is either the mistaken elevation of an instrumental good into a basic good or the mistaken characterisation of a combination of two goods as a unitive basic good. These contentions are born out by Finnis's own comments about marriage in Natural Law and Natural Rights.

As noted above, the first requirement of basic reasonableness is to have a coherent life plan. In analysing this requirement, Finnis notes a number of projects which one might adopt in order to achieve particular basic goods:

\footnotetext{
${ }^{27}$ Finnis, Natural Law and Natural Rights, at 91.
} 
Commitment to the practice of medicine (for the sake of human life), or to scholarship (for the sake of truth), or to any profession, or to a marriage (for the sake of friendship and children) $\ldots$ all require both direction and control of impulses, and the undertaking of specific projects. ${ }^{29}$

I am taking this passage out of context. Nevertheless, it demonstrates Finnis's understanding, in Natural Law and Natural Rights, that marriage is in some way instrumental to the goods of friendship and children (life/procreation) in much the same way as the practice of medicine is in some way instrumental to the good of life and scholarship is instrumental to the good of knowledge. Such an understanding is consistent with Finnis's overall methodology, set out above, but not with his argument as set out in "Law, Morality and Sexual Orientation".

Finnis's argument in "Law, Morality and Sexual Orientation" is also problematic with regard to other aspects of his general theory of natural law. In Natural Law and Natural Rights, he makes a number of other general points about the basic goods:

More important than the precise number and description of these values is the sense in which each is basic. First, each is equally self-evidently a form of good. Secondly, none can be analytically reduced to being merely an aspect of any of the others, or to being merely instrumental in the pursuit of any of the others. Thirdly, each one, when we focus on it, can reasonably be regarded as the most important. Hence there is no objective hierarchy amongst them. ${ }^{30}$

The second point in the above paragraph goes a little further than the point already made: basic goods are not instrumental or derivative in any sense, not even to or of other basic goods. The third point in the above paragraph is that there is no objective hierarchy between the goods. Finnis's argument against the recognition of same-sex partnerships, principally the assertion that there are eight basic goods including life, friendship and marriage, is profoundly problematic in the light of these requirements of natural law theory. The problem with Finnis's argument against the recognition of same-sex partnerships, apart from its treatment of marriage as a basic good comprised of other

\footnotetext{
${ }^{28}$ Finnis, Natural Law and Natural Rights, at 91.

${ }^{29}$ Finnis, Natural Law and Natural Rights, at 104. Ellipsis original.

${ }^{30}$ Finnis, Natural Law and Natural Rights, at 92.
} 
basic goods, is that it necessarily introduces a ranking of basic goods. In his characterisation of same-sex partnerships as inimical to the good of marriage, notwithstanding the ignored extent to which they are instrumental to the basic good of friendship, Finnis effectively ranks the good of marriage above that of friendship. Finnis might respond, however, that this arises not because of a preference for marriage over friendship, as basic goods, but rather because of the fact that marriage is a basic good whereas same-sex partnerships are, at best, only instrumental to a basic good.

This response, however, points up the crux of the problem. It would perhaps be permissible to rank marriage - as an instrument - above same-sex partnerships as the former promotes two basic values (life and friendship), whereas the latter promotes only one (friendship). ${ }^{31}$ However, when the instrument of marriage is characterised as a basic good, against all the methodological injunctions set out in Natural Law and Natural Rights, any such ranking becomes an implicit ranking of the goods themselves. This becomes clear if one considers something that might be instrumental to marriage, such as tax breaks for married couples. If marriage is a self-evident good, such an instrument could plausibly be seen as a secondary good. However, that which is instrumental to friendship, such as same-sex partnerships, is deemed illegitimate. This implies a ranking of the good of marriage over the good of friendship.

A response to this argument is to maintain that the basic goods are not being ranked. Instead, this response argues, same-sex partnerships are bad not because marriage is more important than friendship but rather because same-sex partnerships harm marriage whereas tax breaks for married couples do not damage any basic good. However, it is not the case that natural law theory prohibits all acts that harm basic goods. As noted earlier, natural law theory prohibits acts that are intended to do nothing but harm to a basic good. When one act, objectively speaking, both serves one basic good and damages another basic good, one determines its legitimacy by focusing on intention. This emerges from Finnis's discussion of the doctrine of indirect effect. As noted above, Finnis argues that it is permissible indirectly to damage a basic good in one's pursuit of another basic good, but it is impermissible directly to damage a basic good. This substantive distinction imposes a methodological need to distinguish between individuated and non-

\footnotetext{
${ }^{31}$ Even if this argument is sound, it is unclear that it applies to other heterosexual partnerships. At the very least, further arguments would have to be found.
} 
individuated acts. One does this through reference to the intention with which the acts are performed:

Fundamentally, a human act is a that-which-is-decided-upon (or -chosen) and its primary proper description is as what-is-chosen. A human action, to be humanly regarded, is to be characterized in the way it was characterized in the conclusion to the relevant train of practical reasoning of the man who chose to do it. On the other hand, the world with its material (including our bodily selves) and its structures of physical and psycho-physical causality is not indefinitely malleable by human intention. The man who is deciding what to do cannot reasonably shut his eyes to the causal structure of his project; he cannot characterize his plans ad lib. $^{32}$

On this basis, it is difficult to see how choosing a same-sex partnership can be morally unacceptable. Even if marriage is a basic good, and even if that basic good is damaged by same-sex partnerships, such damage is inflicted indirectly. That is, such damage is an incidental side-effect of the person's efforts to pursue the good of friendship. This respects the person's own characterisation of her action, the reason why she has acted in this way. Perhaps Finnis could avoid this problem, and thus maintain his position against the recognition of same-sex partnerships, by characterising marriage as a more important good than friendship, but such a move is wholly incompatible with his basic position that there is no hierarchy as between the basic goods. In short, Finnis has provided no basis on which a position against the recognition of same-sex partnerships can be reconciled with his general natural law theory.

Based on these observations, one can develop two responses to Finnis's overall argument against the recognition of same-sex partnerships. The first, which is of limited use and value, amounts to little more than a personalised attack on Finnis himself. This response would argue that the tension between Natural Law and Natural Rights and "Law, Morality and Sexual Orientation" illustrates that, for Finnis, the category of supposedly basic and self-evident goods is infinitely expandable to meet the demands of whatever moral conclusion is desired in a particular context. This argument is, I think, of limited value as it seeks to draw inferences about Finnis's state of mind from his writings. Although this

32 Natural Law and Natural Rights, at 122. Internal cross-references omitted. 
might be a worthwhile focus of inquiry for a psychologist or a biographer, it is of little assistance to the working out of moral justifications. For even if the argument is sound and I am unsure as to whether it is - it provides no direct response to the argument actually advanced in "Law, Morality and Sexual Orientation". Finnis and, a fortiori, anyone else would still be entitled to stand over that argument. For these reasons, this response is argumentatively useless for those concerned to rebut the moral propositions advanced by Finnis in "Law, Morality and Sexual Orientation".

The second and, I think, stronger argument is that Natural Law and Natural Rights provides compelling reasons, from natural law theory itself, as to why the natural law argument against the recognition of same-sex partnerships is deeply flawed. That argument, at least as advanced by Finnis, fundamentally relies on the characterisation of marriage as a basic, self-evident good. For it is only that characterisation that allows same-sex partnerships to be viewed as an illusory (and therefore damaging) instantiation of a basic good, rather than as an instrument to promote another basic good, that of friendship. This characterisation of marriage as a basic good, however, constitutes unsound natural law theorising in that it either mistakes an instrument for a basic good or it creates a new basic good out of a combination of two other basic goods. The proposition that marriage is a basic good, essential to Finnis's argument, is not a valid proposition of natural law theory. The argument must therefore fail.

\section{Privacy Arguments in Favour of Same-Sex Partnership Recognition}

As noted at the outset of this article, most of the early political objectives in the gay rights movement were secured through reliance on privacy arguments. The typical structure of such arguments is that the State should not interfere in each individual's zone of personal autonomy, leaving the individual to make her own moral judgments within that zone. Such arguments, although often presented as being amoral (ie, as being neutral as between competing moral visions) do themselves reflect a particular moral position, namely that the state should not impose any moral vision (even one preferred by a majority of its citizens) within that zone of personal autonomy.

Privacy arguments are not the preserve of liberals. Even Finnis, as noted above, endorses a form of the privacy argument in deigning, on the grounds of subsidiarity, to criminalise the homosexual activity that he strongly argues to be wrong. The overall argument of 
Finnis, however, amply demonstrates the limited value of privacy arguments from the perspective of a gay rights advocate. For it is entirely possible for one to advocate privacy, as Finnis in a sense does, while maintaining a moral position against some of the activities that persons engage in within that private zone. (Despite the criticisms that I have made of Finnis's moral argument against partnership recognition, his privacy position is, in the abstract, a tenable moral position.) Same-sex partnership recognition, however, is on any account a matter in the public zone: it is all about the public recognition to be given by the state to a private relationship. Thus privacy arguments, however successful they may have been in relation to the decriminalisation of homosexual activity, provide no support for the recognition of same-sex partnerships. ${ }^{33}$

\section{Egalitarian Arguments in Favour of Same-Sex Partnerships}

The possibility of a strictly egalitarian argument

Bamforth contends that egalitarian arguments do not provide a sound basis for same-sex partnerships. He makes a number of tactical arguments, which do not concern this paper, but also suggests that egalitarian arguments are question-begging and incapable of supporting a case for partnership recognition. He reasons:

For to say that two persons (or couples) are morally equal, we need to explain $w h y$, in normative terms, they deserve to be viewed in this way. The concept of equality cannot, in and of itself, provide us with an answer - for at root, the term "equality" is simply a descriptive label telling us that two persons (or couples) deserve analogous treatment, rather than why such treatment is deserved. ${ }^{34}$

Bamforth argues that an argument deeper than equality is needed in order to answer that "why?" question. This scepticism of equality arguments in the context of same-sex partnerships reflects a general scepticism, on the part of some philosophers and legal thinkers, of the worth of equality arguments. Bamforth cites two in particular: Peter Westen and Joseph Raz. Westen states the position as follows:

\footnotetext{
${ }^{33}$ For a slightly more detailed consideration of this issue, see Nicholas Bamforth, "Same-Sex Partnerships and Arguments of Justice" in Robert Wintemute and Mads Andenaes (ed.), Legal Recognition of Same-Sex Partnerships: A Study of National, European and International Law (Hart, Oxford, 2000).

${ }^{34}$ Bamforth, "Same-Sex Partnerships and Arguments of Justice", at 40.
} 
[T] o say that people who are morally alike in a certain respect "should be treated alike" means that they should be treated in accord with the moral rule by which they are determined to be alike. Hence "likes should be treated alike" means that people for whom a certain treatment is prescribed by a standard should all be given the treatment prescribed by the standard. Or, more simply, people who by a rule should be treated alike should by the rule be treated alike. So there is its: equality is entirely circular. It tells us to treat like people alike; but when we ask who "like people" are, we are told they are "people who should be treated alike". Equality is an empty vessel with no substantive moral content of its own. Without moral standards, equality remains meaningless, a formula that can have nothing to say about how we should act. ${ }^{35}$

Westen essentially argues that equality is an entirely formal concept, requiring only that rules which are stated to apply to a particular class should be applied to all members of that class. As such, it provides no independent basis on which one could criticise a particular rule: equality does not tell us what is a good rule; equality only reminds us to apply rules impartially. Put in other words, equality provides no guidance as to what is a just distribution of goods in society. I shall consider Westen's argument in more detail below. Before doing that, it is necessary to address Raz's argument.

\section{Raz's argument}

Raz distinguishes between strictly egalitarian principles and rhetorically egalitarian principles. ${ }^{36} \mathrm{He}$ considers the following as the paradigm of a strictly egalitarian principle:

All Fs who do not have $G$ have a right to $G$ if some Fs have $G .^{37}$

This principle is sensitive to existing inequalities among members of the relevant group with respect to the relevant benefits. Under this strictly egalitarian principle, it is not the case that all people are entitled to G. Nor is it the case that all Fs are entitled to G. An F is entitled to $G$, only if other Fs actually have G. One can secure compliance with this

\footnotetext{
35 Peter Westen, “The Empty Ideal of Equality” 95 Harvard Law Review 537, at 547 (1982). The closest philosophical forerunner of Westen is probably Richard Flathman, "Equality and Generalization: A Formal Analysis" in Nomos 9: Equality (J. Roland Pennock and John Chapman ed, Atherton Press, New York, 1967), p.38. For a brief discussion, see Oran Doyle, Constitutional Equality Law (Round Hall Thomson, Dublin, 2004), at 3-4.

${ }^{36}$ Joseph Raz, The Morality of Freedom (Clarendon Press, Oxford, 1986), chapter 9.
} 
strictly egalitarian principle either by giving $G$ to those Fs who do not yet have $G$, or by depriving $\mathrm{G}$ from those Fs who already have it. In the language of constitutional law, one can level up or level down. Theories which are dominated by such principles are, in Raz's language, strictly egalitarian theories. ${ }^{38}$

There are, however, other theories and principles that may produce equalities or that may make use of the language of equality but are not themselves strictly egalitarian. For instance, principles of entitlement generate equality in some respect in that all who have equal qualification under them have an equal right. As an example, say that all unemployed people are entitled to $€ 200$ a week from the state. This principle produces an equality of treatment for unemployed people but it is not, according to Raz, a strictly egalitarian principle because a strictly egalitarian principle is not the basis for the treatment. In such principles, egalitarian ideas may serve a useful argumentative function, but they do not identify the normative basis of the principle. In contrast, a strictly egalitarian theory is one in which strictly egalitarian principles provide the normative basis for the argument and, in so doing, dominate all other distributive principles.

Raz observes that a theory consisting entirely of egalitarian principles would have absurd consequences:

The only intrinsic goods and ills such principles admit of are relational ones. If they constitute the entire foundation of morality then the happiness of a person does not matter except if there are other happy people. Nor is there any reason to avoid harming or hurting a person except on the ground that there are others who are unharmed and unhurt. The absurdity of this view is seen by the fact that we only have reason to care about inequalities in the distribution of goods and ills, that is of what is of value or disvalue for independent reasons. There is no reason to care about inequalities in the distribution of grains of sand, unless there is some other reason to wish to have or avoid sand. ${ }^{39}$

\footnotetext{
${ }^{37} \mathrm{Raz}$, The Morality of Freedom, at 225.

38 By dominated, Raz means that the principles are rarely or never overridden by other considerations and that the principles apply to the main cases to which the theory applies. Raz, Morality of Freedom, at 233.

${ }^{39}$ Raz, Morality of Freedom, at 235.
} 
Now it is the final sentence and a half of this proposition on which Bamforth relies to argue that egalitarian principles, whatever their argumentative assistance, provide no normative basis for recognition of same-sex partnerships:

In relation to the legal entitlements of lesbian and gay individuals or couples, such a reason can only be found in a deeper justification for granting legal protection, suggesting that it is that justification which should - in the interest of clarity - be used in the first place. ${ }^{40}$

But this reads too much into what Raz actually says. For Raz's criticism - if that is the word - is not of egalitarian principles per se but rather of theories which rely solely on egalitarian principles. In referring to the distribution of grains of sand he does not, at least at this point, mean to indicate that egalitarian principles are of no relevance to distributional issues, but rather that it would be nonsensical to have a theory consisting solely of egalitarian principles. Indeed, his idea of a strictly egalitarian theory, as noted above, is one in which egalitarian principles dominate non-egalitarian principles. In such a theory, one must rely on other principles to identify what constitute goods and ills. However, egalitarian principles are the dominating force on the distribution of those goods and ills.

These general observations about the structure of egalitarian arguments can be applied to the partnership recognition debate. If one accepts that partnership recognition is a good, it seems to follow that everyone should be entitled to partnership recognition. This, however, is not a strictly egalitarian argument. For the normative basis for this entitlement is not egalitarian but rather the status of partnership recognition as a good. ${ }^{41}$ There may be an egalitarian by-product of this argument: partnership recognition being accorded to everyone. One could even introduce egalitarian rhetoric into the argument: “equal partnership recognition for all!”. But the normative basis of the argument is not equality. In order for a partnership recognition argument to be strictly egalitarian, the egalitarian principle must be dominating. It is possible to formulate a partnership recognition argument in such terms. For one can - in theory at least - subordinate the good-identifying argument to Raz's paradigm of an egalitarian argument.

\footnotetext{
40 Bamforth, "Same-Sex Partnerships and Arguments of Justice", at 40.

${ }^{41}$ Bamforth suggests autonomy as a basis on which partnership recognition might be a good; I shall return to this argument later.
} 
This argument can be loosely formulated as follows. Partnership recognition is a good. However, if some people are entitled to partnership recognition, all people must be entitled to partnership recognition. This second distributional principle dominates the first good-identifying principle for the following reasons. As noted above, the paradigmatic strictly egalitarian principle can be achieved either by levelling up or by levelling down. It is this characteristic that marks it as strictly egalitarian because by this characteristic the strictly egalitarian principle can defeat a good-identifying principle, holding that it is better for none to have the good than for some to have it. Thus the dominating egalitarian principle in the current argument could be satisfied either by according partnership recognition to all or by denying partnership recognition to all. As partnership recognition is identified as a good, it follows that recognition for all is preferable to recognition for none. However, as the egalitarian principle dominates, recognition for none is preferable to recognition for some. If it were otherwise, the egalitarian principle could not be said to dominate and this would not be an egalitarian theory. In this light, one can rephrase the point of strictly egalitarian principles in the following way. The import of a strictly egalitarian principle on the distribution of a good is that it is better for none to have a good than for only some to have it. Or one can look at the same proposition from the other side: if an argument holds that it is better for none to have a good than for some to have it, then such an argument is strictly egalitarian.

This illustrates that one can have an egalitarian argument in support of partnership recognition. However, it is necessary to note briefly a number of reservations one should have about the egalitarian argument just formulated. First, I have indicated only the structure of such an argument. This leaves open the question of whether the good of partnership recognition really should be subordinated to the strictly egalitarian principle. Secondly, the argument is loose as to what is meant by the good of partnership recognition. Does the slogan "partnership recognition is good" mean that people should have partnerships recognised, regardless whether they recognition for the partnerships that they have formed? There is no necessary reason why this proposition should not be the case. However, if one thinks that there must be a desire for recognition (on the part of both parties) in order for recognition to be a good, then one must identify more precisely what one means by "partnership" and what one means by "desire for 
recognition". For the time being, I shall assume that the good of partnership recognition incorporates the idea of desire for recognition (in the form of a joint desire to have that relationship recognised by the state). ${ }^{42}$ Thirdly, the argument does not specify what groups are connoted by the words "all", "some" and "none". This raises another crucial issue about egalitarianism and I shall consider it below.

Before doing that, however, it is necessary to consider Raz's argument further, as it has subtleties not alluded to by Bamforth. He posits two further distinctions: one between satiable and insatiable principles; the other between diminishing and non-diminishing principles. The demands imposed by satiable principles (e.g. "Everyone's needs should be met) can be completely met, and diminish as they are met. The demands imposed by insatiable principles (e.g. "Everyone should have as much pleasure as they can enjoy") can always (in principle) be satisfied to a higher degree. However, some insatiable principles may be non-diminishing and some may be diminishing. Principles with no distributive implications - such as "It is good if each has as much wealth as can be secured" - are non-diminishing, insatiable principles. A person is not less entitled to more wealth simply because she already has wealth. This produces unacceptable consequences in the cases of conflict; strict egalitarian principles can be seen as an attempt to modify the non-diminishing insatiable principles in order to ensure that the unacceptable consequences do not arise. Raz argues, however, that non-diminishing, insatiable principles are invalid principles of justice: fundamental principles of justice are all diminishing. As such, strictly egalitarian principles add nothing to a theory of justice on that front as there are no valid non-diminishing principles the effects of which must be mitigated. I do not, in this paper, wish to disagree on that point.

Raz also argues that there is no case for relying on egalitarian principles to modify diminishing principles because such principles themselves provide guidance in cases of conflict. The fact that the force of the principle diminishes as it is satisfied means that, in cases of conflict, the principle itself will tend to resolve the conflict in a way which produces egalitarian results, although such results are a by-product, and do not directly reflect the normative basis for the distribution. Thus, egalitarian principles add nothing to

\footnotetext{
42 When I later consider the form of partnership recognition, I shall have to address questions such as whether the relationship must be sexual in nature and whether consent is an important pre-requisite for recognition.
} 
satiable, diminishing principles. As such, strictly egalitarian principles - although valid in form - can add nothing to any theory of justice and should be rejected.

Raz's conclusion on this point turns fundamentally on the proposition that strictly egalitarian principles can add nothing to a theory of justice as the only valid principles in such a theory are diminishing principles and such principles do not need to be regulated by egalitarian principles. He reasons as follows:

Do [egalitarian principles] have any role in regulating the operation of [diminishing principles]? Only if they identify a source of concern which, even though it does not affect the outcome, improves our understanding of why the outcome is the right one. There is no way of conclusively proving that egalitarian principles fail to identify such a concern. But wherever one turns it is revealed that what makes us care about various inequalities is not the inequality but the concern identified by the underlying principle. It is the hunger of the hungry, the need of the needy, the suffering of the ill, and so on. The fact that they are worse off in the relevant respect than their neighbours is relevant. But it is relevant not as an independent evil of inequality. Its relevance is in showing that their hunger is greater, their need more pressing, their suffering more hurtful, and therefore our concern for the hungry, the needy, the suffering, and not our concern for equality, makes us give them the priority. ${ }^{43}$

It seems to me that this reasoning has reached its conclusion too quickly. As Raz notes, the strictly egalitarian principle can be satisfied in one of two ways: levelling up or levelling down. ${ }^{44}$ However, he later suggests that levelling down would be inconsistent with any plausible theory of justice:

Egalitarian principles would be indifferent between achieving equality through taking away from those who have and giving to those who have not. The implausibility of such a view points to the existence of additional fundamental principles which at least establish a preference for the non-wasteful option. ${ }^{45}$

\footnotetext{
43 Raz, "Equality", at 240.

${ }^{44}$ Raz, "Equality", at 226.

45 Raz, "Equality", at 235.
} 
Raz is too quick to label this proposition "implausible". It may be implausible with regard to tangible goods, such as bread, water or dwelling places. However, it is far from clear that it is implausible with regard to intangible goods, such as partnership recognition. ${ }^{46}$ Consider the following. Let us assume that the electoral franchise is a good. It follows, on Raz's reasoning, that it is better for more people to have this good than for fewer people to have it. However, is it better for nobody to have the franchise than for a limited group of people to have it? That is, is a system of government such as North Korea's dictatorship better than that of Apartheid-era South Africa? It does not seem implausible to argue that a dictatorship is better than "democracy" with a racially limited franchise. This is not to argue that a dictatorship is a good form of government: far from it - it denies the electoral franchise which is conceded to be a good. However, it is to argue that a democracy with a racially limited franchise is worse than a dictatorship.

The only way, I suggest, in which such a proposition can make sense is if one concedes a role to strictly egalitarian principles in regulating the operation of diminishing principles of justice - that is, if one concedes that the argument in favour of the electoral franchise can, in some cases, be regulated (made subordinate to) strictly egalitarian principles. Raz might respond that the very notion of the electoral franchise incorporates the idea that it is a franchise for all: as such, Apartheid-era South Africa was not a valid instantiation of an electoral franchise and the comparison with North Korea's dictatorship proves nothing. But I do not think that this objection is sound. It is not inherent in the idea of electoral franchise that it is a franchise for all. ${ }^{47}$ Such a view can only derive from the incorporation of egalitarian principles within the good in the first place. Such incorporation would again concede vitality to egalitarian principles but at a conceptual level adds little, if anything, to the concept of egalitarian principles regulating the operation of diminishing principles of justice.

There is a further way in which one can perceive independent force for egalitarian principles. Raz's satiable and diminishing goods are themselves insensitive to different

\footnotetext{
46 I think that partnership recognition can be classed as a satiable, diminishing good because it is clearly something that one can acquire fully (unlike Raz's example of pleasure) and it is diminishing because the more partnership recognition one has (in this case, one either has it or one does not), the less reason there is to give one more of it. In this regard, Raz notes that satiable principles are invariably diminishing principles.

${ }^{47}$ It may follow from the acceptance of the electoral franchise as a good, that it is a good which should be provided to all (subject to whatever restrictions can be objectively justified). However, this does not mean
} 
distributions. Imagine that in a situation of equal hunger, there is enough bread to relieve the hunger of $90 \%$ of the population. Of itself, the satiable and diminishing good is indifferent to whether the $10 \%$ who do not receive the good are selected randomly or on the basis of some other criterion, such as race, religion or sexual orientation. If there is force to the contention that the distribution that singles out members of a particular racial or ethnic group for starvation is worse than a distribution that randomly selects the same number of people to starve, that force can only derive from some egalitarian principle that has independent vitality.

Raz is thus wrong to conclude that strictly egalitarian principles have no role to play in a theory of justice. At the very least, strictly egalitarian principles have a potential role to play in regulating the operation of diminishing principles of justice, where those principles identify intangible goods, such as the electoral franchise. However, once it is established that strictly egalitarian principles have independent force in one context, one must concede the possibility that they have independent force in other contexts, even if they would in those other contexts lead to the same result as the diminishing principles of justice themselves. That is, there is no requirement to limit one's theory of justice to exclude strictly egalitarian principles.

A number of points may be made about these strictly egalitarian principles. First, although they have most force with relation to goods and ills, they may have application to the distribution of items which are not themselves goods or ills. For instance, one might have reason to object to a law which provides that white people are entitled to grains of sand, but black people are not, even if grains of sand are not considered to be a good nor an ill. Secondly, strictly egalitarian principles appear concerned with the results of distribution, not the process of distribution. That is, it is not conscious decisions to discriminate that are wrong, but rather inequality in the actual distribution of goods. An unequal distribution that occurs by accident is as much a concern as an inequality that occurs intentionally. Thirdly, although one identifies the independent existence of such principles where they have a levelling-down effect, this does not mean that they only have force in such a situation. That is, having been obliged by one context to concede independent force to such principles, one must concede the possibility of independent force in all contexts. For instance, one must concede at least the possibility that the 
slogan "Partnership Recognition for All!" relies on strictly egalitarian principles as well as on the diminishing principle of partnership recognition. Fourthly, if one considers a number of restrictions on the electoral franchise, it is quickly apparent that some unequal distributions of the good cause more concern than others. For instance, an exclusion of black people from the franchise causes more concern than an exclusion of children. Any account of the substance, as opposed to the form, of egalitarian principles must be sensitive to this phenomenon.

For these reasons, I do not think it is strictly necessary to demonstrate that partnership recognition is itself a good that is subordinate to strictly egalitarian principles in the same way as the electoral franchise. The electoral franchise example indicates a good that is subject to strictly egalitarian principles, thereby indicating the independent vitality of such principles. If those principles have independent vitality in one context, it follows that they may have vitality in other contexts, even if they support the same conclusion as the diminishing principle of justice itself. In such a situation, one might say that the theory is egalitarian, but not strictly egalitarian, in that it could be based either on strictly egalitarian principles or on diminishing principles of justice. Nevertheless, I shall argue that partnership recognition, as a good, is regulated by strictly egalitarian principles and that, as a result, the most coherent arguments in favour of partnership recognition are strictly egalitarian arguments.

\section{Westen's argument}

Although these arguments deal with Raz's points, they do not address those of Westen. Thus, Bamforth could possibly defend his position, along the lines advocated by Westen, by focusing not on the good and the reason for its distribution (which can be egalitarian) but on the differentiations between persons. Westen's point is that equality cannot itself tell us who is alike and who is unalike. As such, Westen argues, the only function of equality is to remind us that rules should be applied to all to whom they are stated to be applied. The logically anterior question of who is actually "alike" is a substantive question of rights, and not a matter of equality at all. Bamforth might modify his argument along these lines to suggest that, while an argument for partnership recognition could have an egalitarian structure, the determination of who is alike for the purposes of recognition

be bread unless everybody had it. 
cannot be a matter of equality, because equality only tells us to treat like persons alike; it does not tell us who is alike.

However, there appears to be little reason why one should accept that arguments as to which equality is more important are not egalitarian arguments. Westen's conclusions on this point follow from his purely formal definition of equality. He derives this from Aristotle's proposition on equality:

Equality in morals means this: things that are alike should be treated alike, while things that are unalike should be treated unalike in proportion to their unalikeness. $^{48}$

Based on Aristotle's statement of equality, Westen advances his own idea of equality as a formal concept:

[E]quality is an entirely formal concept: it is a "form" for stating moral and legal propositions whose substance originates elsewhere, a "form" of discourse with no substantive content of its own. ${ }^{49}$

It may be that this purely formal conception of equality follows from Aristotle's proposition, although it is surely worth noting that Aristotle himself did not view his propositions on equality as being limited to formal equality. ${ }^{50}$ However, Westen's conception of formal equality does not follow from the strictly egalitarian principles identified by Raz. Those principles are again formal in the sense that they potentially capture a number of different arguments as to why it is wrong to provide a good to some persons unless that good is provided to other persons who are equally entitled to it. However, there is no reason to refuse to describe such substantive reasons as "egalitarian". We know that they are not simply substantive entitlements (or rights) because the whole point of an egalitarian principle, as demonstrated above, is that it potentially overrides a right. But if such substantive reasons are not derived from substantive entitlements and if we are not allowed to call them "egalitarian", how are we

\footnotetext{
48 Aristotle, Nicomachean Ethics V.3.1131a-1131b (W. Ross trans. 1925), extracted in Peter Westen, "The Empty Idea of Equality" 95 Harvard Law Review 537, at 543 (1982).

${ }^{49}$ Westen, "The Empty Ideal of Equality", at 577-578. References omitted.

${ }^{50}$ See Wolfgang von Leyden, Aristotle on Equality and Justice: His Political Argument (Macmillan, 1985).
} 
to describe them? Most people would intuitively describe these arguments as "egalitarian"; indeed, "egalitarianism" is the heading in political philosophy under which such arguments, given their form, most readily fall. It may be that work is needed to relate the intuitive understanding of such arguments with a coherent philosophical position, but this is no reason why they should not be called "egalitarian". Westen's position on this issue is only defensible if equality is, as Westen defines it to be, inherently formal. But this is the rub: Westen's position is only true by definition. If an alternative, philosophically credible interpretation exists, there is no reason to accept Westen's definition.

\section{Bamforth's autonomy argument}

Bamforth, having rejected egalitarian arguments, ultimately argues for the recognition of same-sex partnerships on the basis of autonomy. He argues that sexual/emotional desires, feelings aspirations and behaviour are of central importance for human beings. ${ }^{51}$ He then considers the effects of laws and social practices which (implicitly) deny that autonomy:

Laws and social practices which target any social group as a recipient deserving of unfavourable treatment could be said to objectify members of that group: the members, unlike non-members, are stigmatised as being undeserving of full consideration as human beings because of a characteristic or characteristics which they are assumed to possess by virtue of their actual or perceived group membership. A group will typically be singled out for hostile treatment where some element of social sensitivity or controversy attaches to it. ${ }^{52}$

If this is not an egalitarian argument, it is difficult to see what is. It is the differential restriction of autonomy - as distinct from restriction of autonomy simpliciter - that seems to concern Bamforth.

\section{Conclusions}

The discussion on egalitarian principles can be summarised as follows. Many theorists have asserted that justice claims should not be formulated in terms of equality. Some, such as Westen, argue that equality is a purely formal concept and involves no more than

\footnotetext{
${ }^{51}$ Bamforth, "Same-Sex Partnerships and Arguments of Justice”, at 41.
} 
the impartial application of rules. Others, such as Raz, argue that the very form of egalitarian principles can add nothing to a theory of justice. From these different perspectives, both Westen and Raz agree that substantive goods - not equality - are the stuff of a theory of justice. However, it has been demonstrated that strictly egalitarian principles provide a form of justice argument that is not expressed by theories of substantive goods. For this reason, egalitarian arguments have some vitality in justice theories. Although the form of such egalitarian arguments leaves open many questions most crucially that of equality between whom - there is no reason why those questions should not be viewed as egalitarian questions. They certainly cannot be viewed as solely questions about the relative importance of substantive goods. For these reasons, egalitarian arguments are relevant to any discussion of partnership recognition.

\section{Equality Arguments and Partnership Recognition}

The most important feature that an equality argument must capture in order to be convincing is the way in which inequalities as between some persons or groups is of more concern than inequalities as between other persons or groups. Very broadly speaking, there are two competing accounts of equality on this point: process equality and substantive equality. Under process equality, what is important is the process of differentiation which amounts to unequal treatment. Such a process must rationally take account of only relevant differences between different persons or groups. Provided it does so, equality is observed. Under substantive equality, what is important is the relative position of groups in society. Where one group is unjustly subordinated, it would be wrong to exacerbate that position of relative subordination; further, one should act to remedy the situation. ${ }^{53}$

There is much academic debate as to which of these constitutes the better understanding of equality. This perhaps misses the point: both capture values that we consider important. I have argued in a different context that we should be more concerned to advance substantive equality than process equality because currently substantive inequality is much more entrenched than process inequality. For present purposes, however, I wish to make a different point. If one accepts that partnership recognition is a

\footnotetext{
52 Bamforth, "Same-Sex Partnerships and Arguments of Justice", at 43.

${ }^{53}$ For discussion on the parameters of these conceptions of equality, see Oran Doyle, Constitutional Equality Law (Roundhall Thomson, 2004), at 201-231. The account I provide there is mediated somewhat by limits on judicial power. No such limits apply in this context.
} 
good and that the relevance of a strictly egalitarian principle is that it provides an independent basis for arguments as to how that good should be distributed, it seems that one's conception of equality should be more sensitive to the actual distribution of goods than to the process through which such goods are distributed. That is, one should favour a substantive conception of equality over a process conception. I shall operate on this basis for the purposes of this paper.

I have elsewhere outlined a substantive conception of equality that turns on status groups and the need to avoid the unjust subordination of already unjustly subordinated groups. On this analysis, gay people are a status group in that they, to varying extents, conceive of themselves as a group, are conceived of by others of a group and their status is tied to their membership of that group. They are subordinated within society in a number of ways. Of most relevance to the present issue is the denial of partnership recognition to them. That is, although gay people can have partnerships recognised by the state $-i e$ they can get married - they can only do so by denying what they are and opting into heterosexual marriage. ${ }^{54}$ In this way, the basic structure of subordination of gay people in current times is much the same as it has always been: acceptance and respect within society is possible, but only to the extent that one pretends to be what one is not. The closet lives on. This focus on status ties this conception of equality quite closely to the context in which, considering Raz's arguments, we considered that egalitarian principles most clearly had force: the distribution of intangible goods. For the reason why people want intangible goods is because of what such goods say about a person's place in society, their status. To deny an intangible good is to deny status. It is to say: although this good costs us nothing to give, we deny it to you simply because you are not worthy you are inferior to us.

Now it is of crucial importance to this conception of equality that it only prohibits the unjust subordination of already unjustly subordinated social groups. This does not mean that one must find an argument, outside of equality, as to why the subordination is unjust, but rather that one may conclude that inequality for some groups or in some circumstances, is justified. For this reason, it must address arguments to the effect that,

\footnotetext{
${ }^{54}$ Indeed, as a matter of Irish law, it is questionable whether gay people have the requisite capacity to form valid heterosexual marriages. See $C v C$ [1991] 2 IR 330. As a side issue, this raises the possibility that, in Ireland, it is not simply the case that gay marriage is not allowed but rather that gay people are excluded from all marriage. This changes slightly the contours of the debate.
} 
although the denial of partnership recognition amounts to subordination, it is not unjust either because it is just to subordinate homosexuals generally or because it is just to subordinate homosexuals in this particular way. Although many moral arguments have been put forward to this effect, I propose here to deal with those advanced by Finnis and discussed earlier in this article.

In this regard, the justice arguments for the subordination of homosexuals generally and for the subordination of homosexuals particularly through the denial of partnership recognition run in parallel. For the general subordination argument appears to turn on the fact that sex is an act directed to the production of human life (a good) and nonprocreative sex is inimical to that good of human life. This is similar in form to the more particular argument that marriage is a basic human good and any form of partnership which purports to be marriage but does not have that unique synthesis of friendship and life-production is inimical to that basic good of marriage. I have already outlined the flaws with the marriage argument: it simply posits marriage as a basic good, in contravention of the general methodology of the natural law. As such, it provides no reason, beyond bald and questionable assertion, as to why same-sex partnership recognition would be wrong. There are similar flaws with the general sex argument for unless one makes life subordinate to the good of marriage (and, quite apart from the problems of recognising marriage as a basic good, natural law methodology again prevents this), non-marital sex would have to be regarded as a legitimate means of advancing a good while non-procreative marital sex would be illegitimate. The position against homosexual acts can only be maintained by introducing other distinctions that are unacceptable for the natural law theorist. In this way, the justice arguments for both the general subordination of homosexuals and the particular subordination through the denial of partnership rights both founder on the insuperable difficulties of developing a coherent and justified set of distinctions which endorse marital non-procreative sex, but prohibit non-marital procreative sex. Non-procreative marital sex is of course a good thing: it is instrumental to the good of friendship (and, indeed, play). By the same token, homosexual sex is instrumental to the good of friendship, a good that is also served by the recognition of same-sex partnerships. For all these reasons, I suggest that there is no basis in justice for the denial of partnership recognition to gay couples. 


\section{The forms of partnership recognition}

In the light of these various moral arguments about partnership recognition, it is appropriate to consider the various forms of partnership recognition that are currently proposed. This is not intended as a detailed discussion of current proposals, but rather an attempt to clarify the moral implications of various forms of partnership recognition.

\section{Retrospective partnership recognition (the presumptive scheme)}

In many ways, this is not partnership recognition at all. Under this approach, the state retrospectively recognises non-marital partnerships when the partnership comes to an end, either through death or through dissolution. When the partnership comes to an end, the state makes such property adjustment orders as appear just and could provide tax breaks equivalent to those afforded to married couples in relation to their property. This could be done either on a generic or a case-by-case basis.

Typically, the trigger for such retrospective partnership recognition is a certain amount of time lived together. For instance, if two persons have lived together for three years (leave aside for present purposes the character of that relationship) and one dies without having made a will, the intestacy rules might be amended to be more favourable to the other party. The advantage of such an approach is that even people who do not formally enter into a relationship receive some protection. Others, however, construe this as a disadvantage in that people may become subject to obligations that they have not voluntarily undertaken. More seriously, people who have consciously decided not to seek recognition from the state may find themselves unwillingly saddled with such recognition. This objection could be overcome, however, by making the scheme presumptive only, ie by allowing people to opt out of it.

Of more relevance to the current concerns, however, are the egalitarian implications of such a stance. As suggested above, one can divide partnership recognition into two aspects: symbolic and practical. The practical impact of retrospective recognition is important: persons are protected from unfortunate events and, depending on the extent of legal measures possible upon retrospective recognition, could be put into effectively the same situation as heterosexual, married couples where a marriage comes to an end, either through death or separation. The symbolic impact of retrospective recognition is, however, much less. For the state is effectively saying that non-marital partnerships are 
only deserving of recognition once they are over. Most people who want their partnership recognised would, I suggest, want it recognised while still in existence. This lack of symbolic impact is of particular concern for egalitarian principles which turn on comparative recognition. Retrospective recognition of partnerships effectively denies non-marital partnerships the intangible elements of recognition for as long as there is anything there that can be meaningfully recognised.

\section{General partnership recognition (contractual)}

Under this approach, any two people could, upon application, have their partnership recognised by the state. One can imagine various procedures and substantive requirements that would have to be met, but these are unimportant for present purposes. This recognition would thus be available to heterosexual and homosexual partnerships, but also to non-sexual partnerships, such as that between two sisters who have lived their lives together in one house. It is difficult to deny the justice of the claims of that latter group of people. For why should the state, in its formal recognition of people's personal relationships, confine itself to sexual relationships? There are other types of relationships, very important for those involved in them. Any reconfiguration of partnership recognition laws should make some provision for people in long-term personal but nonsexual relationships who would like such relationships recognised by the state.

However, one wonders how many people in non-sexual relationships would want their relationship recognised in this way. Such an approach would cause difficulties if one person were to meet someone else and wish to marry that person. Presumably one could not be married and in a civil partnership at the same time. Would one have to divorce your sister, for example, in order to get married? This points up the issue that the relationships between elderly sisters, although raising mutual moral rights and duties and although they should be protected and recognised in some way by the state, are not really the same as sexual relationships. Most importantly, I suggest, people in such relationships do not aspire to the same exclusivity that is generally accepted as the ideal in sexual relationships. Thus, although non-sexual long-term relationships deserve protection, it is doubtful whether a contractual civil partnership scheme, broadly analogous to marriage, is the best method of providing that protection. 
From the perspective of egalitarian principles, one would also have reservations about the limits of this approach. For, although not as blatant as blanket non-recognition for same-sex relationships, it could be seen as a form of the closet in that it would allow the state (or society) to pretend that homosexual relationships have more in common with asexual relationships than with heterosexual relationships. The ultimate in state recognition - marriage - would be reserved for heterosexual relationships. In this way, the state would again provide practical benefits for same-sex couples while still denying status to such couples. For these reasons, while there are merits to a general partnership recognition scheme of this type, if it leaves marriage as an option for heterosexuals and implicitly equates homosexual relationships with asexual relationships, it would be objectionable on egalitarian grounds. The primary objection here is not to non-sexual relationships being equated with homosexual relationships, but rather to heterosexual relationships being elevated above homosexual relationships. That said, the combination of the two amounts to a powerful statement against homosexual relationships: such relationships will only be recognised by the state because the state can pretend that they are not really sexual relationships. The sexual relationships of homosexuals are not recognised for what they are; homosexuals themselves remain invisible to the law.

\section{Civil recognition scheme for same-sex partnerships}

Such an approach would address some of the egalitarian concerns with retrospective recognition and general partnership recognition. However, it would still implicitly elevate marriage (and by extension heterosexual relationships) over homosexual partnerships. Even if precisely the same benefits were afforded to each type of relationship, the implicit statement of the state, given the generally positive cultural associations with the word "marriage", would again be that homosexual relationships are inferior to heterosexual relationships. This would be an inequality for which no justification has been shown.

\section{Civil recognition scheme for all partnerships, in addition to opposite-sex marriage}

This form of recognition poses the same egalitarian concerns, although considerably diluted, as civil recognition only for same-sex partnerships. Again, the implicit statement of the State is that homosexuals are less worthy than heterosexuals as only the latter are entitled to the ultimate good of partnership recognition in the form of marriage. However, the force of this statement is in this case mitigated as it is provided that 
heterosexuals may also choose civil recognition as an alternative to marriage. Thus, heterosexuals are still held up as being more worthy than homosexuals, but the sting of this statement is lessened by the fact that civil recognition is not deemed to be an option beneath heterosexuals.

\section{Gay marriage}

It might follow from the discussion thus far that the most egalitarian solution to the partnership recognition issue is to allow gay people to get married. However, the institution of marriage raises egalitarian concerns of its own. This is because of the extent to which it is gendered, ie the extent to which it ascribes presumptive gender roles to the partners. Those who choose to marry choose an institution in which the following roles are presumptively assigned according to gender: child-rearing, wage-earning, mealcooking, lawn-mowing, lightbulb-changing, blocked-drain-cleaning, clothes-washing, rodent-killing, etc. These roles are not rigid; many married couples can and do negotiate (in a loving way) the roles that each partner will play. However, such negotiation takes place against a background of what is assumed appropriate for each partner, given their sex.

It would be wrong to single out the institution of marriage as being responsible for these gender roles. To a certain extent, marriage probably reflects general societal ideas of what is appropriate work for men and women. To that extent, presumptive gender roles might persist in heterosexual civil partnerships. However, marriage remains more marked in this respect, for marriage explicitly and unashamedly celebrates ascribed gender roles in its very essence: marriage is a union of "husband" and "wife". For this reason, the presumptive gender roles in marriage are stronger than the presumptive gender roles in a heterosexual civil partnership.

Why should this matter? What is wrong with ascribed gender roles? The problem is that ascribed gender roles form the basic structure of the subordination of women. Whereas the structure of subordination of gay people turns on self-denial and public denial, the structure of the subordination of women turns on role differentiation as between men and women. Women as a subordinated group in society have traditionally lost out through the division of labour as between men and women. The relative emancipation of women has largely consisted of challenges to that division of labour. 
As an institution, marriage reinforces that role differentiation and - in so doing reinforces the subordination of women. Same-sex relationships challenge role differentiation as between men and women because it is necessary (and not just possible) that at least one partner adopt a role that is traditionally ascribed to the opposite sex. In this way, same-sex relationships can be a wider egalitarian force in society, helping to dismantle generally accepted ideas of appropriate gender roles. This egalitarian potential could be undermined, however, if same-sex partnerships were to be recognised through the form of marriage. For by labelling one member of a same-sex partnership "husband" and the other "wife", the partners would not only indicate their willingness to conceive of their relationship in terms of wholly inappropriate gender roles but also undermine the challenge that same-sex relationships in general pose to ascribed gender roles. For these reasons, it can be argued that gay marriage is an appropriate, egalitarian response to the question of same-sex partnership recognition. ${ }^{55}$

Against this, however, it could be argued that nothing would undermine gender roles within marriage more than opening it up to same-sex couples. Although in the shortterm there might be a tendency to "gender-ise" the same-sex partners, in the long-term the more likely impact would be to "de-gender-ise" the opposite sex partners within marriage. Given this potential, and given the unique and generally positive cultural resonance of marriage, the only truly egalitarian approach is to allow gay people to marry.

\section{Civil partnership recognition for all!}

If one continues to have egalitarian reservations about marriage, however, a scheme of civil partnership open to all, combined with the abolition of state marriage, would be the most appropriate egalitarian response to this issue. Given the abolition of staterecognised marriage for heterosexuals, there would be no inegalitarian concerns in making such civil recognition available to non-sexual, personal relationships, as well as to homosexual and heterosexual relationships. On the other hand, one could give different names to the recognition of sexual and non-sexual relationships. As each is a new

\footnotetext{
55 There is a symmetry between this position and that advocated by Finnis. The difference is that Finnis believes that homosexuals would be bad for marriage because marriage is for partners of the opposite sex. I am suggesting that marriage would be bad for homosexuals because marriage is for partners of opposite gender.
} 
institution, there would be no implicit denigration of the form of relationship recognised by the other.

Such an approach would not prevent individuals or communities (religious or otherwise) adopting their own definitions of marriage. Thus a couple could choose to get married in the Catholic church, for example, and also have their relationship recognised by the state in the form of a civil partnership. However, the state would not deem this form of relationship to be more worthy than any other committed relationship, whether a heterosexual partnership not sanctified by a church or a homosexual partnership.

\section{Conclusions}

In the current political context, it is most unlikely that Ireland will opt for the abolition of state recognition for marriage coupled with a civil partnership scheme of this type. In that context, I suggest that a civil recognition scheme open to all sexual relationships and incurring all the rights and obligations of marriage. At the same time, there should be a retrospective, presumptive scheme that would provide minimal, but significant, rights to people who lived together in a relationship of mutual support. The benefits would be provided retrospectively, ie after the relationship ends. Such an approach would meet the needs of non-sexual couples without inappropriately preventing them from forming sexual relationships; it would not impose stringent rights on obligations on people without the consent of those people. Conversely, if people in sexual relationships want those rights and obligations, they always have the option of having their partnership recognised.

\section{Conclusion}

This paper has tried to assess a number of moral arguments concerning the recognition of same-sex partnerships. This was done in the belief that this is an essentially moral issue. My suggestion is that natural law arguments, traditionally most opposed to the very idea of homosexuality, do not provide a coherent basis for opposing same-sex partnerships. I accept that there are other arguments, apart from natural law arguments, against same-sex partnerships. For this reason, the conclusions I draw are open to critique on other grounds. That is work for another day. Nevertheless, I have argued that egalitarian principles provide a compelling basis for arguments in favour of same-sex partnership recognition. When one considers the precise form that such recognition 
should take, one encounters competing egalitarian concerns. Nevertheless, an approach that is sensitive to the iniquity of differential recognition provides the most compelling analysis of the issue. 